\title{
As interfaces entre o ensino de ciências e a psicologia do desenvolvimento: a contribuição de Vigotski
}

\section{The interfaces between science teaching and the psicology of development: the contribution of Vigotski}

\author{
${ }^{1}$ Luiza Oliveira \\ 2 Rose Mary Latini rose.latini@gmail.com \\ 3 Valmir Sbano
}

\section{RESUMO}

Este artigo discute interface entre o Ensino de Ciências e um de seus fundamentos, a Psicologia do Desenvolvimento. O conceito de desenvolvimento humano é geralmente apresentado como processo de estruturação psicológica da infância até a fase adulta. Uma abordagem do Ensino de Ciências está associada a este modelo e valoriza a investigação sobre os mecanismos universais do funcionamento psicológico no processo de construção de conhecimento, produzindo práticas educativas que negam as diferenças entre os sujeitos no processo de desenvolvimento. E, além disso, produzindo um panorama da aprendizagem científica que propõe que no desenvolvimento intelectual da criança não há interação entre os conceitos espontâneos e os conceitos científicos, mas antes uma fronteira, entre as idéias criadas por um desenvolvimento mental prévio à realidade, oriundo das operações psicológicas universais, e as concepções científicas. Estudamos o desenvolvimento psicológico a partir de outra vertente teórica acerca dos vínculos entre o cultural e o universal, a abordagem histórico-cultural. A psicologia de Vigotski descreve o desenvolvimento como um processo que acontece na inserção do homem na cultura, o que leva a compreensão da subjetividade como sendo a produção da singularidade ao longo da história coletiva. Esta ênfase epistemológica engendra novo modo de entender a formação das funções psicológicas superiores e, consequentemente, a formação dos conceitos, prevendo uma relação dialética entre os conceitos espontâneos e os conceitos científicos. Trata-se de um artigo teórico, que faz uma revisão de literatura em obras significativas da psicologia de Vigotski.

Palavras-chave: Psicologia do Desenvolvimento, Ensino de Ciências, Formação de Conceitos, Vigotski.

\begin{abstract}
This article discusses the interface between science education and one of its foundations, the Developmental Psychology. The concept of human development is generally presented as psychological structuring process from childhood to adulthood.An approach to science education is associated with this model, which values research on the universal mechanisms of psychological functioning in the process of knowledge construction, producing educational practices that deny the differences between subjects in the development process. And besides, producing an overview of the scientific learning that suggests that the child's intellectual development there is no interaction between spontaneous concepts and scientific concepts, but a border between the ideas created by a previous mental development to reality, arising universal psychological operations, and scientific conceptions. We studied the psychological development from another theoretical aspect about the links between the cultural and the universal, historical-cultural approach. The Vygotsky's psychology describes the development as a process that happens in the insertion of man in culture, which leads to understanding of subjectivity as the production of uniqueness along the collective history. This epistemological emphasis engenders new way to understand the formation of higher psychological functions and consequently the formation of concepts, forecasting a dialectical relationship between spontaneous concepts and scientific concepts. This is a theoretical article, which makes a literature review on significant works of Vygotsky psychology.
\end{abstract}

Keywords: Developmental Psychology, Science education, Concepts of training, Vygotsky.

1 Instituto de Psicologia; Programa de Pós-Graduação em Ensino de Ciências da Natureza e Programa Stricto Sensu em Psicologia/UFF.

2 Instituto de Ciências Exatas e Programa de Pós-Graduação em Ensino de Ciências da Natureza/UFF.

3 Instituto de Psicologia/UFF. 


\section{INTRODUÇÃO}

Este artigo tem por objetivo discutir a interface entre o Ensino de Ciências e um de seus fundamentos, a Psicologia do Desenvolvimento. Trata-se de um artigo teórico, que faz uma revisão de literatura em obras significativas da psicologia de Vigotski - A Formação Social da Mente; Pensamento e Linguagem; Imaginação e Criação na Infância.

Existem modelos que tradicionalmente aportam estes campos de saber - Ensino de Ciências e Psicologia do Desenvolvimento. Tais modelos se ancoram em duas tendências filosóficas - o idealismo, para a qual o psíquico é manifestação do interior do homem, e lugar da verdade, e o objetivismo, que entende o fenômeno psíquico como resultado de seus determinantes externos. Estas tendências fragmentam a realidade ao evidenciarem a subjetividade como anterior e independente da dimensão concreta da relação Sujeito-Cultura-Linguagem.

A ruptura com os modelos tradicionais do desenvolvimento humano não pode prescindir da análise epistemológica da díade sujeito-objeto, pois a forma como esta relação é definida institui diferentes conceitos de desenvolvimento humano no campo da Psicologia e, consequentemente, diferentes formas de pensar a constituição das funções psicológicas superiores, engendrando, portanto, diversos objetos, métodos e formas de intervenção nas práticas sociais.

O aporte teórico que embasará a interlocução entre a Psicologia do Desenvolvimento e o Ensino de Ciências, neste artigo, remete a uma abordagem epistemológica que está fundamentada no princípio e no método do materialismo dialético de Marx e Engels.

Totalmente ao contrário do que ocorre na filosofia alemã (de Hegel e seus seguidores), que desce do céu à terra, aqui se ascende da terra ao céu. Ou, em outras palavras: não se parte daquilo que os homens dizem, imaginam ou representam, e tampouco dos homens pensados, imaginados e representados para, a partir daí, chegar aos homens de carne e osso; parte-se dos homens realmente ativos e, a partir do seu processo de vida real, expõe também o desenvolvimento dos reflexos ideológicos e dos ecos desse processo de vida (...) Não é a consciência que determina a vida, mas a vida que determina a consciência (MARX; ENGELS, 1977, p. 37).

O psicólogo russo viu nesta forma de descrever a relação do homem com a realidade a solução para a dicotomia entre o cultural e o universal, entre sujeito e objeto na Psicologia do Desenvolvimento. Vigotski, então, explicou a transformação dos processos elementares em processos complexos a partir da dialética constituinte do método do materialismo dialético (COLE; SCRIBNER, 2007).

O método pode ser entendido na obra de Vigotski (2003) pela centralidade que o autor dá ao conceito de linguagem na constituição de seu objeto de estudo. A linguagem é constitutiva do desenvolvimento humano: o significado da palavra é composto pelo significado propriamente dito - convenção arbitrária estabelecida entre o significante e o significado que compõem um signo (fala exterior) - e o sentido - o que indica o significado da palavra para cada indivíduo (fala interior). Assim, o sujeito se constitui pela internalização (fala interior) de processos interpsicológicos (fala exterior); são os mecanismos de aprendizado que movimentam o desenvolvimento, sendo fundamental a mediação de outros, a mediação da cultura. Portanto, o processo de subjetivação para Vigotski (MOLON, 2010) acontece com uma intervenção de membros socialmente mais maduros, que dão sentido a como ser numa e pertencer a uma determinada cultura.

É o processo dialético entre fala interior e fala exterior que constitui a subjetividade. Vigotski (1984), assim, não dá lugar ao solipsismo do sujeito e nem à determinação imediata do ambiente. A fala da criança, que é inicialmente essencialmente social, é transferida para a esfera das funções psíquicas superiores. Logo, entendese que os padrões de comportamento, o conhecimento já circulante na Cultura, são internalizados, pela mediação da fala egocêntrica. Porém, não é esta uma via de mão única, pois a fala interior retorna em atividade criadora, o que evidencia a dialética na constituição do sujeito. 


\begin{abstract}
Além da atividade reprodutiva, é fácil notar no comportamento humano outro gênero de atividade, mais precisamente a combinatória ou criadora. Quando, na imaginação, esboço para mim mesmo um quadro do futuro, digamos, a vida do homem no regime socialista, ou o quadro de um passado longínquo de vida e luta do homem pré-histórico, em ambos não reproduzo as impressões que tive de sentir alguma vez. Não estou simplesmente restaurando a marca de excitações anteriores que chegaram ao meu cérebro, pois nunca vi, de fato, nem esse passado nem esse futuro. Apesar disso, posso ter a minha ideia, a minha imagem, o meu quadro (VIGOTSKI, 2010, p. 13).
\end{abstract}

Entretanto, não é apenas a imaginação que se origina da experiência, mas esta também se apóia na imaginação. Por exemplo, “(...) quando uma criança estuda geografia ou história, quando por meio de uma carta, tomamos conhecimento do que está acontecendo a uma outra pessoa, em todos esses casos a nossa imaginação serve à nossa experiência” (VIGOTSKI, 2010, p. 25).

É a partir desta perspectiva que pensaremos as relações entre as concepções prévias (conceitos espontâneos) da criança e o conceito científico haurido da realidade.

Sendo assim, o aporte teórico da Psicologia Histórico-Cultural de Vigotski apresenta uma nova possibilidade para a Área de Ensino de Ciências em sua interface com a Psicologia do Desenvolvimento, pois explica o porquê de não podermos subordinar exclusivamente a aprendizagem ao abandono dos conceitos espontâneos em prol dos conceitos científicos.

\begin{abstract}
Um conceito cotidiano da criança, por exemplo 'irmão', é algo impregnado de experiência. No entanto, quando lhe pedimos para resolver um problema abstrato sobre o irmão de um irmão, como nos experimentos de Piaget, ela fica confusa. Por outro lado, embora, consiga responder corretamente a questão sobre ‘escravidão', 'exploração’ ou 'guerra civil’, esses conceitos são esquemáticos e carecem da riqueza de conteúdo proveniente da experiência pessoal. Vão sendo gradualmente expandidos no decorrer das leituras e dos trabalhos escolares posteriores. Poder-se-ia dizer que o desenvolvimento dos conceitos espontâneos da criança é ascendente, enquanto o desenvolvimento dos seus conceitos científicos é descendente, para um nível mais elementar e concreto. Isso decorre das diferentes formas pelas quais os dois tipos de conceitos surgem. Pode-se remontar a origem de um conceito espontâneo a um confronto com uma situação concreta, ao passo que um conceito científico envolve, desde o início, uma atitude 'mediada' em relação a seu objeto (VIGOTSKI, 2003, p. 135).
\end{abstract}

Este processo não é importante apenas para a aquisição do conceito científico, mas, sobretudo, para o desenvolvimento do pensamento, pois a aprendizagem científica traz à cena a hierarquia (conceitos de diferentes níveis de generalidade), as inter-relações e a sistematização dos conceitos científicos (conceitos supra-ordenados), que influenciam e permitem o desenvolvimento das estruturas psíquicas.

Por exemplo, "a criança constrói o conceito de gato e o diferencia de outra categoria: carro, por exemplo. Com a aprendizagem escolar, o conceito "gato" será incluído num sistema conceitual de abstrações graduais que partem do objeto concreto e vão alcançando cada vez mais complexidade: gato, mamífero, vertebrado, ser vivo" (REGO, 2001, p. 77).

No desenvolvimento da formação de conceitos, os dois processos se influenciam dialeticamente e é, desta forma, que o vínculo entre pensamento e linguagem se dá. O pensamento reflexivo chega à criança através da sistematização e hierarquia dos conhecimentos científicos, e depois se transfere aos conceitos espontâneos. E, ao mesmo tempo, é fundamental para a generalização, para o pensamento reflexivo, a contextualização trazida pelo conceito espontâneo, oriundo do confronto com as situações cotidianas. A generalização do conceito científico e a concretude do saber espontâneo são pares que operam em relação dialética. O particular (pensamento sincrético, imaginação, concepção prévia), não é obstáculo, mas está em permanente relação com o conhecimento generalizante (conceito supra-ordenado). É isso que permite o pensamento reflexivo, abstrato, fundamental para o desenvolvimento do conceito científico. 
Segundo Vigotski (2003), são as relações entre pensamento e linguagem que instituem a subjetividade para além do sujeito universal e dicotômico de Descartes. A dialética inspirada na teoria de Marx e Engels é também evidenciada no processo denominado de mediação, que revela a interação entre pensamento e linguagem.

A relação do homem com o mundo é mediada por instrumentos e por signos. Assim, Vigotski (2003) estendeu o conceito de mediação presente na teoria de Marx e Engels (1977), ao tratar da relação homem-ambiente, à linguagem, que é um plano mediador fundamental, pois traz conceitos elaborados culturalmente. Logo, da mesma forma que o uso do instrumento transforma a natureza e o próprio homem ao mesmo tempo, a internalização do sistema de signos engendra transformações subjetivas. Este processo dialético se dá na união do pensamento e da fala em pensamento verbal, a partir do diálogo com os membros mais experientes da cultura. Para explicar esta relação dialética entre pensamento e linguagem, Vigotski (2003) descreve o estágio pré-intelectual da fala - no qual, por exemplo, o mesmo som pode expressar diversos significados, sendo, portanto, o outro da cultura quem define o significado. $\mathrm{O}$ autor descreve, ainda, o estágio pré-linguístico do pensamento - 0 qual indica a capacidade de a criança agir no ambiente e resolver problemas práticos sem a mediação da fala. Vigotski (2003), assim, descreve a dialética marxista nas interações psicológicas concretas: explica a passagem de ações realizadas no plano social para ações internalizadas como um processo e é isso que constitui o sujeito, como sujeito singular e coletivo instituído no mesmo ato.

Para entender esta conversão das relações sociais em funções mentais a partir da internalização é fundamental a análise de três outros conceitos da obra de Vigotski (2010), a imaginação, o egocentrismo e a atividade criadora. Tais conceitos estão relacionados entre si, e Vigotski, como sempre, para ser fiel ao método dialético marxista, faz réplica aos sentidos mais comuns dados a estes conceitos. Para ele, por exemplo, imaginação não é um dom para poucos ou um processo que é oposto à realidade, mas a capacidade de criação a partir da reprodução das relações objetivas. Por isso sua indissociação com a memória. Assim, a imaginação é condição necessária da existência. Pela imaginação se incorporam e se exercitam as práticas sociais, mas, também estas práticas assim se modificam, pois a combinação de elementos hauridos da realidade traz a modificação pela marca da singularidade (VIGOTSKI, 2010).

A atividade criadora, segundo Vigotski, é complexa e se desenvolve gradativamente de formas mais elementares e simples para formas mais complexas e depende do acúmulo de experiência. Por isso, a imaginação da criança é mais simples do que a do adulto.

\section{A FORMAÇÃO DO CONCEITO CIENTÍFICO E O ENSINO DE CIÊNCIAS}

Quando analisamos a história da Ciência, percebemos que os conceitos produzidos são resultados de uma imensa experiência anterior acumulada, que traz à cena a ação da imaginação criadora e as dificuldades da objetivação da experiência, bem como a internalização dessa experiência objetivada. Ou seja, há um processo dialético em que as relações externas objetivas (a fala exterior) são internalizadas e necessárias para que a imaginação possibilite novas formas de entender o mundo, que serão também objetivadas, o que evidencia o processo dialético.

Esta tensão, constitutiva do sujeito, é exacerbada nas práticas escolares, pois é a escola a instituição que coloca em cena, sistematicamente, o saber científico diante das concepções espontâneas.

Como consequência desta abordagem para o ensino de ciências, sabemos que é preciso ampliar a experiência da criança para que a atividade de criação aconteça em bases sólidas. Assim, não se pode contrapor o pensamento sincrético, a imaginação, a concepção espontânea à realidade, à concepção científica. Piaget (1976), embora explique a formação do conceito científico, não vê a interação entre os dois tipos de conceitos, afirmando que o conceito espontâneo tem que desaparecer para o científico se estruturar. Para Piaget (1976), a percepção da diferença precede a percepção da semelhança, pois estabelece uma falta de adaptação. Assim, para Piaget (2005), entre os 7 e os 11 anos, as 
operações mentais estão em conflito com o pensamento adulto, com as concepções científicas; seria exatamente esse conflito que geraria a necessidade de adaptação. Tornar-se consciente de uma operação mental significa transferi-la do plano da ação para o plano da linguagem, isto é, recriá-la na imaginação de modo que possa ser expressa em palavras.

Vigotski discorda de Piaget (2003), as crianças se conscientizam das diferenças mais cedo do que das semelhanças, não porque as diferenças levem a um mau funcionamento, mas porque a percepção da semelhança exige uma estrutura de generalização e de conceitualização mais avançada do que a consciência da dessemelhança. Por exemplo, no ensino de química, ao se aprender os conceitos de átomos, elementos, íons e substâncias, os alunos empregam esses conceitos como se fossem intercambiáveis, de mesmo significado. Embora a diferença entre átomos e íons possa ser facilmente identificada pela presença ou não de carga, o conceito científico só entra em "um sistema de relações de generalidade” (VIGOTSKI, 2003, p.116) no momento que esta construção é mediada por outro conceito, o conceito espontâneo. Desta forma, esses conceitos só se generalizam, no momento que os conceitos científicos, através da contextualização, se aproximam dos conceitos espontâneos. Somente a partir desta generalização o aluno é capaz de compreender, conscientemente, por exemplo, a forma como atuam em nosso organismo alguns nutrientes essenciais encontrados nos alimentos, como o ferro, o cálcio, e o potássio, dentre outros. Isto é, as relações de generalidade são essenciais para o estabelecimento da percepção das diferenças entre os conceitos de átomos, elementos, íons e substâncias.

Ainda como exemplo, nos Parâmetros Curriculares Nacionais, do Ensino Fundamental - Ciências Naturais (1998), um dos eixos temáticos é Ser Humano e Saúde. Os temas em Ciências Naturais, atendendo a este eixo temático, podem ser diversos: a água e os seres vivos, erosão do solo, poluição do ar, máquinas, alimentação, entre outros. Tomando, neste exemplo, a alimentação como categoria, pode-se pensar que a criança, antes do saber sistematizado sobre alimentos desenvolvido nas aulas de ciências, é capaz de construir o conceito de fruta e o diferenciar de outra categoria de alimento. Porém, é a escola, com sua proposta de apresentação de um sistema conceitual de abstrações graduais que permite que a criança, partindo do objeto concreto 'fruta', possa o inserir num sistema cada vez mais complexo: fruta, tipos de fruta, tipos de alimentos, composição química dos alimentos, por exemplo, identificação dos nutrientes - macronutrientes que são as bio-macromoléculas (carboidratos, lipídeos, proteínas) e micro-nutrientes (vitaminas e sais minerais). Que ao serem relacionadas com funções orgânicas, se instituem em um sistema ainda mais complexo construindo a categoria de alimentação saudável, por exemplo. Esse processo media o desenvolvimento do pensamento reflexivo, abstrato e não o contrário, isto é, não é preciso esperar o desenvolvimento do pensamento formal para que o ensino sistematizado aconteça. É exatamente este tipo de ensino que ajuda no desenvolvimento do pensamento.

Analisando o ensino de ciências a partir da teoria de Vigotski, entendemos que, diante das propostas curriculares que incluem a Saúde como um tema transversal às ações de ensino na escola, não é possível, por exemplo, apresentar a categoria 'alimentação saudável' como uma generalização pronta. Se isso for feito, a criança repete as recomendações, mas não internaliza os conceitos, apresentando apenas, muitas vezes, uma 'repetição vazia' de conteúdo. Pautando-nos no mesmo exemplo, nem o ensino sobre nutrientes deve apresentar a categoria 'alimentação saudável' como conceito pronto, abstrato (iniciando a aula com conceitos tais como diferenças entre macro e micro nutrientes), nem deve dispensá-lo, e, sim, contextualizá-lo a partir da concretude das concepções espontâneas das crianças.

O aprendizado escolar leva a uma percepção generalizante, pois as concepções científicas com o seu sistema hierárquico de inter-relações constituem a forma com que a consciência e seu domínio se desenvolvem, sendo mais tarde transferidos a outros conceitos e a outras áreas do pensamento. A consciência reflexiva, o pensamento abstrato, chega à criança por meio dos conceitos científicos. A consciência significa generalização, que significa formação de um conceito supra-ordenado, constituído por vários conceitos subordinados hierarquizados em diferentes níveis de generalidade.

Em relação ao conceito aprendido na escola, a relação com o objeto é mediada, desde o início, por outros conceitos: rudimentos de sistematização chegam à criança e são transferidos para os conceitos espontâneos, mudando a sua estrutura psicológica de cima para baixo. 
O aprendizado precede o desenvolvimento das funções psicológicas: a criança aprende certos hábitos e habilidades numa área específica, antes de aprender a aplicá-los conscientemente e deliberadamente.

Porém, segundo Vigotski, há uma relação recíproca entre os dois processos, pois o sujeito se depara com problemas diferentes quando diante das experiências escolares e cotidianas. Na escola, ao ensinarmos um conceito sistemático, o sujeito se depara com a própria forma de pensar o conceito, a abstração. Tem acesso ao objeto, à realidade que ela não vivencia diretamente. Logo, se há diferença no contexto, há diferença no caminho do desenvolvimento.

Na área de Ensino de Ciências ainda hoje grande parte das pesquisas e das práticas escolares mantém a abordagem piagetiana, com a separação e contraposição entre os conceitos espontâneos e os conceitos científicos.

A teoria de Vigotski remete a uma valorização do que chamamos escola concreta, pois é nesse espaço que se realiza de forma sistemática, e com intervenção, o desenvolvimento das funções psíquicas superiores. Nesse sentido, também no aprendizado formal, a experiência precede o desenvolvimento. A criança se desenvolve na medida em que, orientada por aquele que está por mais tempo na regra do jogo, se apropria da cultura. Aprendizado e desenvolvido são indissociáveis.

Assim, segundo Vigotski (1984), a aprendizagem se inicia antes da entrada na escola. Logo, a aprendizagem sistemática da escola se inicia a partir de concepções que a criança se apropriou da sua cultura. A escola promove um modo mais sofisticado de analisar e generalizar os elementos da realidade: o pensamento abstrato. As atividades sistematizadas realizadas a partir dos conceitos científicos (não espontâneos), aprendidos na escola, introduzem novos modos de operação intelectual: o pensamento abstrato. Isto gera novas formas de utilização da linguagem.

A aprendizagem sistematizada tem, portanto, lugar constitutivo na constituição da subjetividade, pois produz a operação mental própria do pensamento abstrato. Assim, o pensamento reflexivo chega à criança através da aprendizagem dos conceitos científicos e se transfere aos conhecimentos espontâneos. Inicialmente afastados, a evolução faz com que os conceitos espontâneos e os conceitos científicos terminem por se encontrar. Embora com direções opostas, são dois processos intimamente relacionados (VIGOTSKI, 2003).

No campo do ensino, esta perspectiva é muito atual e vem promovendo a ideia de práticas escolares comprometidas com a promoção do desenvolvimento humano. A aprendizagem ganha importância, “a criança vai se desenvolvendo à medida em que, orientada por adultos ou companheiros, se apropria da cultura elaborada pela humanidade” (FREITAS, 1995, p. 101). No campo específico do ensino de ciências, traz à cena a ideia de que "o conceito espontâneo abre caminho para o conceito científico e este fornece estrutura para o desenvolvimento daquele, tornando-o consciente e deliberado” (FREITAS, 1995, p. 103).

\section{CONSIDERAÇÕES FINAIS}

A Psicologia proposta por Vigotski traz contribuições para a área Ensino de Ciências, pois engendra uma nova forma de entender a formação dos conceitos, prevendo uma relação diferente entre os conceitos espontâneos e os conceitos científicos. Diferentemente da prática tradicional, em muitos momentos apoiada na psicologia piagetiana, que contrapõe os dois tipos de conceitos, a abordagem da psicologia histórico-cultural evidencia a relação entre ambos, o que gera perspectivas de práticas e metodologias diferentes no Ensino de Ciências. É preciso, porém, avançar nos estudos, pois embora seja a formação do conceito científico o objeto que apresenta a psicologia de Vigotski, nas primeiras traduções dos anos de 1980, as pesquisas em ensino de ciências ainda não se apropriaram das premissas dessa psicologia social, o que, sem dúvida, compromete as contribuições para as metodologias desenvolvidas na sala de aula. 


\section{REFERÊNCIAS}

COLE, M.; SCRIBNER, S. Introdução. IN: VIGOTSKI, L. A Formação Social da Mente. 7 edição. São Paulo: Martins Fontes, 2007.

BRASIL. Secretaria de Educação Fundamental. Parâmetros curriculares nacionais: Ciências Naturais/ Secretaria de Educação Fundamental. Brasília: MEC / SEF, 1998.

FREITAS, M.T.A. Vygotsky e Bakhtin: Psicologia e Educação - um intertexto. $2^{\mathrm{a}}$ edição. São Paulo: Editora Ática, 1995.

MARX, K; ENGELS, F. A ideologia alemã. São Paulo, Grijalbo, 1977.

MOLON, S.I. Subjetividade e Constituição do Sujeito em Vygotsky. $3^{\mathrm{a}}$ edição. Petrópolis: Vozes, 2010.

PIAGT, J. A Representação do Mundo na Criança. 2a edição. São Paulo: Idéias \& Letras, 2005.

A Equilibração das Estruturas Cognitivas. Rio de Janeiro: Zahar, 1976.

REGO, T.C. Vygotsky: uma perspectiva histórico-cultural da educação. 10ª edição. Petrópolis: Vozes, 2001.

VIGOTSKI, L. Imaginação e Criação na Infância. São Paulo: Ática, 2010

Pensamento e Linguagem. 2ª edição. Petrópolis: Vozes, 2003.

A Formação Social da Mente. São Paulo: Martins Fontes, 1984. 